\title{
DOCUMENTOS
}

\section{Concolorcorvo isería Fray Calixto San Joseph Tupac Inga?}

I773 aparece como fecha de la publicación de un libro titulado El Lazaritlo de ciegos caminantes. Como pie de imprenta del mismo, el de Rovada, Gijón, España. Su autor, Calixto Bustamante Carlos Inga, alias "Concolorcorvo" - con el color del cuervo- quien dice que la obra se ha hecho a base de las memorias de Alonso Carrión de la Vandera sobre el viaje y comisión que tuvo, por encargo de la Corte, para el arreglo de Correos y Postas desde Montevideo a Lima. Los bibliógrafos afirman que el libro fue editado en la capital peruana y que es una impostura hacerlo aparecer en Gijón. Lo han asegurado con su prestigio de investigadores, Brunet, José Toribio Medina y Rubén Vargas Ugarte entre otros.

Es El lazarillo nota de expresión popular en que se unen la novela picaresca, el diario de viajes y los cuentos incásicos en un desfilar de paisajes y costumbres, con la ironía del indio y la sátira española, a lo Quevedo, dentro de una tendencia criticista. El diálogo fluye ameno entre el español Carrión de la Vandera y su acompañante en el viaje desde Buenos Aires, Concolorcorvo. Ventura García Calderón ha dicho que esta obra "inaugura en el Perú una tersa y sabrosa mezcla de retórica de indio cazurro con español lenguaraz". El cuadro de costumbres surge ameno y bien delineado a través de este recorrido sudamericano, con la crítica a flor de diálogo, descubriendo debilidades de uno y otro lado. Además de sabrosa lectura es, asi, documento para el esclarecimiento his- 
tórico; referencia precisa de aquellos años ya revueltos de la segunda mitad del siglo xvII. La chispa ingeniosa y malevolente surge desde el momento en que el autor asegura ser "indio neto", salvo "las trampas" de su "madre", de las que no sale "por fiador". Y sus bromas y lisuras envuelven a "indios y mestizos", que son peores que gitanos. Pero no escapan los españoles de sus dardos venenosos, aunque exalte la obra de Amat, en expresión de funcionario o tal vez de reacción popular contra los ataques a ese Virrey por determinados círculos aristocráticos o jesuitanos. La obra está salpicada de observaciones agudas, con risa que se esconde detrás del documento. Relieva la personalidad de Peralta y Barnuevo, pero se ríe de los culteranismos y de la afición por conocimientos ajenos a la realidad misma de América. Ridiculiza a gentes de las grandes ciudades que están desarrollándose en la América española y contrasta risueñamente a peruanas y mexicanas para terminar con aquel ingenioso juego de peruleros y gachupines que insertatía -un siglo después- Palma en su tradición "Las cuatro PPPP de Lima". Se trata de una producción al par ingeniosa y documental, que of rece tal vez el más interesante acopio de datos de la sociedad sudamericana de entonces, después de las noticias secretas de Juan de Ulloa; a más de ser, por supuesto, magnífico itinerario al servicio de la Geografía.

En cuanto a su autor, los hay que sostienen la veracidad de lo que se dice en la portada, o sea que se trataba de un indio o mestizo, nacido en el Perú, y cuyo nombre bien podria ser el de Calixto Bustamante Carlos Inga, para el que no hay biografía. Mientras otros autores han expresado la tesis de que "Concolorcorvo" es un español -concretamente Antonio Carrión de la Vandera- que empleó la superchería de aparecer como indio para poner en boca de éste lo que no podría decir como funcionario hispano. Dentro de estos últimos se alinea Federico Monjardín, quien opinó que Concolocorvo no era sino el anagrama de Carrión de la Vandera (?). Asimismo Walter Bose, quien, además, hace la biografía de éste último. Informa, así, que Antonio Carrión de la Vandera era natural de Gijón (Asturias) y que en 1773 pasó a México para luego seguir a Lima el año siguiente, donde casó con Petronila de Matute; que en $177^{1}$ fue nombrado Visitador y Superintendente de Correos, para hacer un reconocimiento personal de la línea postal desde Montevideo hasta Lima y que para ello, regresó a América a bordo del paquebote "El Tuçumán", Hegando a Montevideo el iI de mayo de ese año; que en Buenos Aires se entrevistó con el administrador Domingo de Basavilbazo y el ro de noviembre partió al interior; y que durante el viaje redactó extensas 
memorias. Asegura Bose que en Potosí le ofreció sus servicios un tal Calixto Bustamante Carlos Inga, que babiat sido criado del Presidente del reino de Chile, Antonio Gill Gonzaga; y que seguramente a la muerte de éste se trasladaría a Lima a probar fortuna y de allí al Cuzco. Que se conoce de él una falsificada carta de recomendación para sí mismo, que firmaba el secretario del Virrey Martín de Martirena y dirigida al ya citado administrador de Correos Domingo de Basavilbazo. Bose piensa que Carrión de la Vandera redactó la mayor parte del texto e intervino directamente en los diálogos explicando su actuación, para reivindicarse de las calumnias de sus enemigos. Lucas Guerra, en una tesis presentada a la Universidad del Cuzco para graduarse de doctor en Letras, añade a las opiniones de Bose que Carrión de la Vandera publicó la obra bajo el nombre de su servidor, a manera de butla o de venganza, zahiriendo a los habitantes del Perú, y concluye expresando categóricamente que "Concolorcorvo" es aquel visitador español quien compuso una obra que es "lesiva para la cultura peruana"; y "apócrifa", porque considera que un indio no hubiera impreso los ataques que ahí se hacen sarcásticamente a los nativos peruanos. La romántica posición de Guerra, basada en una reacción sentimental y poco científica, no soluciona el problema, pues "Concolorcorvo" - "con el color del cuervo" - desliza su ironía tanto sobre indios como sobre mestizos y españoles; y El lazarillo pertenece a un tipo de obras satíricas, en las que frecuentemente se ataca a los propios connacionales y los vicios de la sociedad en que vive el autor, sin que pueda deducirse por ello que pertenece a tal o cual raza; o a tal o cual nacionalidad; o que es un extranjero, enemigo del país al que así se refiere y critica. Por el contrario, la predilecta simpatía que "Concolorcorvo" manifiesta por el Perú, por Lima y por el Cuzco, en comparaciones con otras capitales y lugares de América, lo ponen en la condición de peruano o perulero. El anagrama de Monjardín es, asimismo forzadísimo y lo más serio de estas opiniones está en los aportes biográficos de Walter Bose. El P. Rubén Vargas Ugarte daba por cierto, en cambio, la condición de indio o de natural del Perú del citado Concolorcorvo. Ventura García Calderón sostiene que debió ser un mestizo ladino, tinterillo y leguleyo. Luis Alberto Sánchez insiste en que se trata de un indio socartón que estuvo en España y que conocía bien la literatura europea, pero que sobre todo conocía profundamente el Perú y otros países sudamericanos.

Tras la pista de un autor que tuviera estas características y con biografía por ostentarse, es como he encontrado en La imprenta en Lima de José Toribio Medina, la figura de un mestizo, descendiente de incas, 
en quien creo se puede personalizar al autor de El lazarillo. Se trata del hermano Calixto de San José Tupac Inga, miembro de la familia de los Bustamante Carlos, pues era nada menos que sobrino de Juan Bustamante Carlos Inga, radicado éste en España y que aparece citado en el propio Lazarillo, -indirectamente- así como en las cartas y comunicaciones de aquel Hermano Calixto José, a más de referirse a él todos los comentaristas y críticos de aquella obra que lo sindican como persona influyente en la corte española en el mismo siglo xviI.

Fray Calixto de San José fue hijo de Pedro Montes y de Dominga Tupac Inga. Nació en Tarma, de familia cuzqueña y viajó muy joven del Perú a Guatemala en el cortejo del Arzobispo Pedro Pablo Pardo, peruano de nacimiento. Más tarde recorrió América del Sur desde Quito hasta Buenos Aires, en los años que corren entre 1736 y I750. El mismo lo dice: "Como testigo de vista, por haber transitado [por su comisiones] desde Quito a Buenos Aires, desde el año 36 hasta el 1749 cuya provincia componen cerca de dos mil leguas..." etc. Vivió algún tiempo en el Cuzco. Y escribió y llevó ante el rey de España, una Representación ver. dadera y exclamación rendida y lamentable que toda la nación indiana bace a la Magestad del Señor Rey de las Españas y Emperador de las Indias, el señor don Fernando el VI, pidienda los atienda y remedie sacándolos del afrentoso vituperio y oprobio en que están más de doscientos años. (Ver Anejo No $\mathrm{r}$ ). Salió de Buenos Aires y después de una estada en Río de Janeiro, siguió para Lisboa en una larga navegación de la que dice: "No pude comer, ni dormir, por los vómitos tan repetidos que padecí y el mayor vómito que me atravezaba el alma era el no tener plata". (Como puede apreciarse, dentro del mismo estilo del Lazarillo) - En agosto de I750 presenta su petición al rey; y escribe también a los munícipes peruanos quejándose de los delegados que tienen en España, que no hacen sino cobrar dinero y no trabajar por sus representados, a la vez que pide ser él quien los represente, solicitando dinero para pagar los gastos hechos y por hacer, con un lenguaje tinterillesco. En esa y otra comunicación se refiere a su tío Juan (o Antonio) Bustamante Carlos Inga, como gentilhombre de su Majestad y repite iguales conceptos que en El hazarillo acerca de que los monarcas españoles atienden y respetan a los que fucron reyes del Perú. (Ver Anejo 5). El estilo parece identificar ambos escritos en un solo autor. (Ver Anejos 2, 3 y 4). Además de la Representación, escribió en Madrid, un Memorial al Sumo Pontífice, como lo atestiguó su compañero de viaje Fray Isidoro Cala y Ortega de quien él asegura, en su carta al Cabildo de Lima, que lo redactó en latín. Temeroso de las 
persecuciones que pudieran desatarse contra él, consigue una Carta Real, firmada por el propio rey el ro de julio de 1753 , para que a su regreso al Perú lo atiendan en su calidad de miembro de la Orden Seráfica, en la que pasará al Colegio de Misioneros de Urubamba; y se indica allí que "no se le moleste, ni embarace" (Ver Anejo 6). En Lima, según lo expresa Fray Julián de Arriaga, en carta fechada en 1759, es recluido en el noviciado "por castigo de las sugestiones" que ha movido entre los indios; comunicándose con "otros ladinos", y a petición del Virrey Conde de Superunda. (Ver Anejo 7). Al paso por tierras chilenas, se dirige al Presidente de Chile, comunicándole que viaja hacia España en el navio "San Martín" y que "por accidente marítimo" se halla en Valparaíso, en la prisión, solicitando socorro de la Real Hacienda, lo que consiguió dándosele al reo "dos reales diarios". Tuvo así una conexión con el Presidente de la Audiencia de Chile que tal vez le sirviera más tarde (Ver Anejo 8). En diciembre de $x 760$, el Comisario General de San Francisco comunica que Fray Calixto llegó a Cádiz y que será enviado a un Convento de las Provincias de España, "distante de puerto de mar" y "que le prohibe su majestad volver a Indias". Y Fray Antonio de Durand comunicará, luego, que se ha destinado a Fray Calixto de San Joseph, indio de nación, al Convento de la Recolección de San Francisco del Monte, de la provincia observante de Granada, que está en desierto de Sierra Morena, abstraido del comercio de seculares y distante del mar"... (Ver Anejos 9 y ro). Allí purgó sus faltas y trató de remediarlas muy posiblemente con naturales alabanzas a España, sus reyes y sus representantes, pero dejando siempre latente su irónica y crítica actitud. No sabemos cómo regresaría al Perú, pero luego se puso en contacto con el Administrador de Correos Basavilbazo, tal como el propio Walter Bose informa; y conociendo las Memorias de Antonio Carrión de la Vandera injertó en ellas sus propias apreciaciones. Habría que investigar qué relación existió entre Fray Calixto y el "Instituto de Gijón", a que se refiere Luis Alberto Sánchez en su Literatura peruana (T. IV, p. 187), pues como se sabe El lazarillo figura como editado en esa ciudad española.

Los conocimientos de Concolorcorvo acerca de México y Guatemala; la referencia a "las cuatro PPPP" del perulero Pedro Pablo Pardo, tanto en el primero como en el último capítulo de El lazarillo, coincidente con ęl primer viaje de Fray Calixto a Centro América; la sucesión de visiones, çon hondo conocimiento de los medios indígenas, desde Lima a Buenos Aires en viaje invertido; la vinculación con indios y mestizos de sangre real en el Perú y España, descendientes de Melchor de Bustamante Carlos 
Inga; los argumentos, narraciones y argucias ladinas; la tendencia satírica y zumbona, que se esconde tras la seriedad de sus explicaciones, todo conspira a referirse a él como Calixto Bustamante Carlos Inga. Inclusive aquella relación con el Presidente de Chile, que sirvió para la cita de Bose y que puede concretarse - por ahora - a la carta tomada por Medina. Excelente referencia para establecer una efectiva coincidencia entre Fray Calixto de San Joseph y El lazarillo de ciegos caminantes, sería confrontar el estilo de esta obra con el de la carta que dirigió aquél a los cabildantes de Lima y en particular los siguientes párrafos finales:

Señores: para dar cumplimiento de lo que yo les of recí de ser su mensajero ó embajador, en nombre de toda la nación, dí principio de Mi Viaje desde esa ciudad sólo con 8 pesos y ésos prestados, los cuales se los remití desde el camino (no como lo que ban dicbo que con más de 600 pesos babia salido de esa ciudad) con la esperanza de que los caciques, y en particular los parientes del Cuzco, me babian de facilitar con plata; mas no sucedió así (jeso es fiarse de bombres y más de parientes!); finalmente, proseguí mi viaje, comunicando á unos, persuadiendo á otros, y por último llegué á la ciudad del Cuzco, en donde me entendí en comunicar y consultar sobre la materia, y allí sucedieron cosas particulares, que por no alargarme omito; entre todo esto, nunca desistí de mi determinación, siempre constante y animoso. ¿Quién puede hacer esto sino Dios? que por las cosas que me han acaecido lo he experimentado; por lo tanto, voy á manifestarle a vuestras mercedes. Pues viéndome sin esperanzas de socorro, ni de Lima ni de otras partes, determiné consultar con los mayores de celo y de virtud, para que, según lo que saliese de la consulta, determinar de mi viaje; mas, salió al contrario de lo que yo esperaba, de grandes más dificultades, y la mayor era el que no babia plata ni hombres que tal emprendiesen una empresa tan ardua; pero por lo que mira de los escritos, importaba mucho el que Su Majestad lo supiese y Su Santidad también, para remediar tanta calamidad; $y$ dijeron los consultores, encareciendo grandemente que, si ellos fuesen indios babian de saltar por sobre tejados, que aunque supieran venir nadando sobre las aguas y comiendo yerbas, babian de venir á dar á saber á Su Majestad de lo que padecian, pero que los indios no lo barian, asi por no baber bombres entre ellos, $y$, sobre todo, que eran timidos, $y$ otras infinitas cosas dijeron, apocándonos. Habiendo, pues, entendido de la consulta lo referido, hice propósito de emprender mi viaje, y juntamente procuré disimular y hacer deshechas, y para divertirlos más, condescendí á hacer viaje á las montañas de Quillabamba, y cumplidos los tres meses volvi á la ciudad del Cuzco. Mi compañero era uno de los que se balló en la consulta, á quien yo le persuadí á que mirase por nosotros y que se dignase de acompañarme, á que condescendió el dicho compañero, $y$ cuando yo volvi ya tenia las providencias para el viaje. Aséguroles á vuestras mercedes, con la verdad que siempre he profesado decir, así digo para aquí y para ante Dios, que con sólo 6 pesos que dió un cacique depuesto, llamado don Andrés Navarro, dimos principio á nuestro viaje en 25 de Septiembre del 49. Parece cosa increible el cómo nos ban- 
deamos en tan dilatado camino, como son 800 leguas basta Buenos Aires, desde donde empezamos á buscar plata prestada para no desistir de la empresa. La plata que hemos gastado hasta el presente pasan de dos mil pesos. Corrimos por la costa, porque no nos prendieton en el camino, y cuando llegamos á Buenos Aires ya teníamos cartas requisitorias de mi Comisario General; en fin, por sobre todos saltamos; por esto dije que estuvimos escondidos tres meses.

"Señores, á mí me parece ser importante el que don Antonio Chaiguaca se pase á esta corte para ahorrar de abogados; vuestras mercedes procurarán animar á este dicho don Antonio y en tanto que vea letra de vuestras mercedes, Dios, Nuestro Señor, guarde la vida de vuestras metcedes muchos y muy felices años en su amor.-Madrid y Noviembre 14 de $1750 .-\mathrm{M}$. ilustre Cabildo, B. L. M. de vuestras mercedes, su más afecto pariente y seguro servidor.-La misma nada.-Hermano Calixto de San Joseph Tupac Inga".(Anexo 4).

Son tantas las coincidencias y el estilo similar, que permiten presumir holgadamente que este escritor mestizo y sobre todo "socarrón", "ladino", "tinterillo" y "leguleyo" que se llamó Fray Calixto de San Joseph sea el autor de El lazarillo de ciegos caminantes.

Augusto Tamayo Vargas, Universidad de San Marcos, Lima.

BIBLIOGRAFÍA.-Del Autor.-Representación verdadera y exclamación rendida y lamentable, etc. Exclamación de los indios americanos usando para ello de la misma que hizo el Profeta Geremías a Dios en el Capítulo $\mathrm{V}$ y último de sus Lamentaciones (Referencias $257^{6}$ de la Imprenta de Lima de José Toribio Medina) Impresión clandestina. Lima. s/f. $r 748$. El lazarillo de ciegos caminantes, desde Buenos Aires hasta Lima, con sus itinerarios según la más puntual observación, con algunas noticias útiles a los Nuevos Comerciantes que tratan en mulas, y otras históricas. Sacado de las Memorias que hizo don Alonso Carrión de la Vandera en este dilatado viaje. Comisión que tuvo por la Corte para el arreglo de Correos y Estafetas, situación y ajuste de Postas, desde Montevideo. Por Don Calixto Bustamante Carlos Inga, alias Concolorcorvo, natural del Cuzco, que acompañó al referido Comisionado en dicho viaje y escribió sus Extractos. Con licencia. En Gijón, en la Imprenta de la Rovada, año de 1773 .

Sobre el autor Walter B. L. Bose, Don Calixto Bustamante, Carlos Inca, alias Concolorcorvo y El lazarillo de ciegos caminantes. (Actas y 
Trabajos Científicos del XXVII Congreso Internacional de Americanistas), Lima, 1939.-Jacques Charles Brunet, Manuel du Libraire, Tomo I, París, I860, No I 426.-Ventura García Calderón, "Nota preliminar", El lazarillo de ciegos caminantes, Biblioteca de Cultura Peruana, Tomo VI, París, Descleé de Brouwer, I938, págs. 8 a ro.-Lucas Guerra, "Concolorcorvo", o sea el visitador iespañol Antonio Carrión de la Vandera, Tesis presentada para optar el grado de Doctor en la Facultad de Filosofía, Historia y Letras de la Universidad Nacional de San Antonio Abad, Cuzco, Talleres Gráficos, La Económica, 1944- - Martiniano Leguizamón, "Notas bibliográficas y biográficas", El lazarillo de ciegos caminantes, desde Buenos Aires hasta Lima, Buenos Aires, Biblioteca de la Junta de Historia y Numismática Americanas, 1908.-José Toribio Medina, La imprenta en Lima, Tomo III, Santiago de Chile, Impreso y grabado en casa del autor. MCMV, págs. 43 a 46 y 542 a 554.-Ricardo Palma, "Las cuatro PPPP de Lima", Tradiciones peruanas completas, Madrid, Aguilar S. A. de Ediciones, I953, págs. 588 y 589.- Luis Alberto Sánchez, La literatura peruana, Tomo IV, Buenos Aires, Editorial Guarania, I95I, págs. I24 a 128.-Augusto Tamayo Vargas, Literatura peruana, Tomo II, Lima, Ediciones Miranda, I954, págs. 47 y 48; y "Un descubrimiento literario, ¿Quién fue el autor de El lazarillo de ciegos caminan. tes." El comercio, Lima, 29 de junio de I958, pág. 2.-Albetto Tauro, Elementos de literatuna peruana, Lima, Ediciones Palabra, I946. págs. 52 y 53 . 


\title{
Anejos extraídos de la imprenta en Lima
}

\author{
(I $584-\mathrm{I} 824)$ \\ por \\ Jasé Toribio Medina
}

Tomo III

Santiago de Chile

Impreso y grabado en casa del Autor. MCMV

\section{ANEJO No I \\ REPRESENTACION}

2576.-Repre-/sentacion/ verdadera, y ex-/clamacion rendida, y lamenta-/ble, que toda la Nacion India-/ na hace á la Magestad del Señor/ Rey de las Españas, y Empera-/dor de las Indias, el Señor D./ Fernando el VI, pidiendo los/atienda, y remedie sacandolos/del af rétoso vituperio, y opro-/ bio en que están más ha de du-/cientos años. Exclamación de los In-/dios Americanos, usando para ella/ de la misma, que hizo el Propheta/ Geremias á Dios en el Cap. 5. y ul-/timo de fus Lamentaciones.

Fol.-Port, orl.- - v. en bl. -48 hojas. s. f., signadas B.Z, en pliegos de 2 hojas, menos el I. ${ }^{\circ}$ que no tiene signatura.

B. $M$.

Véase el facsímil. 
Impresión clandestina de las prensas limeñas y de mediados del siglo pasado. Esta pieza es una declamación ardorosa en favor de los indios y contra la administración española en América. En la imposibilidad de darla á conocer por entero, trasncribiremos aquí como muestra del tono en que está redactada el párrafo siguiente:

"Bebemos nuestra agua con el dinero, compramos nuestra leña con el precio, porque en las Indias, señor, los indios vuestros vasallos y vuestros hijos, bebemos nuestras lágrimas, que es nuestra agua continua, comprándola con la paga, pues págamos porque nos maltratan y para que llorar nos hagan; compramos, ó los leños, en que nos crucifiquen, ó leña, con que nos quemen y consuman; pagamos nuestra agua, pues pagamos á los curas y pastores de nuestras almas por que nos administren las aguas puras de la gracia, y llevándose copiosísimas cantidades de nuestro sudor, lágrimas y trabajos, estamos á secas y sedientos del saber, entre los cienos y lodazales inmundos de la ignorancia".

Págs. 542-543.

\section{ANEJO No 2}

- "Señor--El hermano Calixto de San Joseph Tupac Inga, á los pies de V.S. dice: Qué sólo dos motivos lo obligan á solicitar que S. M. (que Dios guarde) sea servido determinar sobre los asuntos que contiene la Exclamación que sus lealísimos vasallos los indios remitieron al suplicante á la provincia del Cuzco, confiado en su persona la pondría á los reales pies del Rey, nuestro señor, lo que logró en 23 de Agosto del año de 50.

"El primer motivo es suficiente por católico, cuyo primer objeto debe ser velar por la honra y gloria del Altísimo, esto es, que los católicos cristianos confirmados en nuestra santa fe católica se aparten del gremio de nuestra Santa Madre la Iglesia romana, hostigados y perseguidos de los ministros de Su Majestad, retitándose á las montañas, olvidando nuestros sagrados ritos, volviéndose á su idolatría, siéndole más dócil tan bárbara resolución que tolerar el rigor, aspereza y violencias que padecen y como testigo de vista, por haber transitado (por sus comisiones) desde Quito á Buenos Aires, desde el año de 36 hasta el de I749, cuyas provincias componen cerca de dos mil leguas, lo refiere con la verdad que debe á V. S., para que se sirva dar curso á negocio de tanta importancia. 
"El segundo, por haber nacido de padres de la primera distinción, cuya obligación es mirar y defiender la corona de su rey y señor natural; y aunque no fuera este el primer objeto, será suficiente el amor que le tiene á Su Majestad, por cuyos poderosos motivos of reció con suma complacencia á sus parientes, los Ingas, y gobernadores, encargarse del negocio tan del servicio de las dos Majestades, obligándole salir huyendo de la persecución, sin esperar el segundo correo, por no ser sentido de los ministros de justicia, que sólo deseaban aprisionar su persona para impedir el paso al recurso, como lo hicieron con otros dos, y que nuestro invicto monarca no fuese sabedor y pusiese remedio a ello.

"Estos son, señor, los motivos que le han movido á solicitar el breve y buen despacho de la Representación, en forma de lamentación, de los principales indios; este es, señor, el poder que al presente tiene, pero le espera con toda la mayor amplitud y brevedad, y para calificar su persona y ser éste el motivo de haber pasado á estos reinos, presenta á V. S. las certificaciones adjuntas, interin le llegan las demás comprobadas.

"Suplica á V.S. se sirva coadyuvar al logro de la deseada quietud de aquel reino, pues, de lo contrario, pueden sobrevenir fatales consecuencias, siendo cierto que al suplicante sólo le mueven los motivos referidos; calificando esta verdad el vivir retirado del bullicio y vanidades de este mundo, aspirando sólo á tomar la capilla de lego; esta es sólo su pretensión y deseo, este será el premio de sus desvelos y fatigas, con lo que quedará sumamente gustoso y premiado; espera el suplicante del benigno corazón de V.S. tendrá á bien esta sincera Representación y que pondrá los medios más conducentes al servicio de Dios, del Rey, paz y sosiego de aquel dilatado reino, en que hallará el premio de las dos Majestades y los infelices indios y el suplicante esclavizados eternamente á la persona de V.S., etc."

Págs. 543-544.

\section{ANEJO No 3}

"Señor--El hermano Calixto de San Joseph, Tupac Inga, puesto á los reales pies de Vuestra Majestad, dice: es descendiente del undécimo rey Inga, llamado Tupac Inga Yupanqui, y por esta alianza tiene cercano parentesco con los más caciques del reino del Perú que descienden de sangre real; $y$ deseando que aquellos vastos dominios se conserven en el debido y apetecido vasallaje de vuestra real persona, se encargó de poner en 
vuestras reales manos una Representación de los indios, que á costa de muchos peligros y riesgo de su vida tuvo la dicha de ponerla el día veinte y tres de Agosto de I750, de la que no ha logrado razón, por lo que los indios se hallarán desconsolados viendo se les dilata su alivio; por lo que suplico á Vuestra Majestad se sirva mandar se dé curso á la referida instancia para que logren vuestros vasallos los indios el alivio que desean; $y$ en el caso que se haya tomado alguna providencia que les pueda servir de consuelo, que se le comunique al suplicante para que, instruido della, les pueda escribir, persuadiéndolos á la mayor observancia de la fee y confianza en la real clemencia de Vuestra Majestad, de quien y de el paternal amor esperamos recibir esta gracia.-Señor.Hermano Calixto de San Joseph Tupac Inga".-(Con su rúbrica).

Pág. 544 .

\section{ANEJO $\mathrm{N}^{9} 4$}

"Muy Ilustre Cabildo de la ciudad de Lima.--Muy señores míos:Amados hermanos y queridos parientes.-Señotes alcaldes de la ciudad de Lima, gobernadores y caciques principales, señores nobles de la nación indiana y jefes del batallón de esa ciudad. Participo á vuestras mercedes cómo ya llego el tiempo de que yo manifestase con evidencia los fervorosos deseos que siempre he tenido de aliviar y favorecer á mis amados hermanos y parientes, como lo expresé en varias ocasiones, y principalmente en todas las juntas y consultas que tuvimos después de las fiestas reales de la coronación de nuestro rey y señor don Fernando Sexto (á quien Dios guarde); con este ánimo ó empeño pasé al valle de Xauja, á mediados de Agosto del año 48; y el mismo año, á principios de Noviembre, pasé á la gran ciudad del Cuzco, con el Manifiesto ó exclamación para manifestarla á nuestros parientes, caciques y nobles de dicha ciudad y sus provincias, á fin de conmover sus ánimos para que ayudasen á tan importante obra con alguna limosna; más fue en vano todo mi trabajo y afán, porque ninguno quiso concurrir.

"Viéndome sin auxilio alguno humana, puse esta empresa tan ardua en las manos de Dios, como siempre he acostumbrado en todos mis negocios, para que Su Majestad se dignase de facilitar mi venida á España, si fuese de su agrado; consulté el punto con personas doctas y timoratas, para el mayor acierto, y aunque éstas convinieron en que era muy importante el que la dicha Exclamación se pusiese en las manos del Rey, nuestro 
señor, mas dificultaba el modo de que esto se ejecutase, hasta que comunicándole mi pretensión al R. P. Lector y misionero apóstolico fray Isidoro de Cala y Ortega, el Señor le dió ánimo y valor para que me quisiese acompañar en el viaje, el que comenzamos á ejecutar el día 25 de Septiembre del año pasado de mill setecientos y cuarenta y nueve, hasta llegar a la ciudad de Buenos Aires, que fué el día I5 de Febrero de 50 , sin haber tenido enfermedad alguna en todo ese tiempo. En el pueblo de Santiago de Cotagaita encontramos á don Francisco Zeballos, quien nos dió noticia del motivo de su regreso á esa ciudad de Lima, la que no refiero, porque ya vuestras mercedes la sabrán con su llegada, y también nos participó la mucha dificultad que había de poder pasar á España, así por la vía de Cádiz como por la Colonia de los portugueses, lo cual, en la realidad, lo experimentamos, pero Dios lo facilitó y la plata.

"Pues habiendo llegado á Buenos Aires hicimos cuantas diligencias fueron posibles á fin de lograr el tránsito á España con toda brevedad, por no ser sentidos y que nos impidiesen el pasaje, como al dicho don Francisco. Pasamos á concertar el pasaje con el Marqués de Casa Madrid, que tenía un navío suyo prompto para Cádiz y nos pidió ochocientos pesos, los que no teníamos, por lo cual quedamos sin esperanzas de poder pasar en dicha embarcación. Procuramos valernos de una señora sevillana, vecina de Buenos Aires, quien nos tuvo en su casa escondidos tres días, hasta facilitar nuestro tránsito para la Colonia, el cual conseguimos á fuerza de dinero, porque de otra suerte era imposible; y para esto buscamos plata emprestada, porque no nos sucediese lo de don Francisco Zeballos, que por falta de dinero desistió de su empeño y se volvió á ir.

"Puestos ya en la Colonia, empezamos á respirar de algún modo, por vernos ya libres de que nos estorbasen nuestro intento; y aunque nos hallamos faltos de dinero, por lo mucho que teníamos gastado, no obstante procuramos en la Colonia embarcación para el Río Janeiro, con el deseo de acercarnos más á la Europa y de apartarnos de todo peligro; á los ocho días tuvimos embarcación y en treinta y dos días llegamos al Río de Janeiro con felicidad (gloria á Dios), aunque á mí me fue muy mal en la salud, porque en toda la navegación, hasta llegar al Río, no pude comer ni dormir por los vómitos tan repetidos que padecí; y el mayor vómito que me atravesaba el alma era el no tener plata; y así pueden vuestras mercedes considerar las angustias y aflicciones en que nos habremos visto, hallándonos debiendo más de 600 pesos, sin tener á quien recurrir para que nos remedie nuestras necesidades, porque desde aquí á Lisboa son carísimos los fletes de embarcación, y más caros estuvieron 
para nosotros, porque cuando nosotros llegamos estaba la flota para salir dentro de tres días; por esta razón dije lo que llevo dicho de las angustias en que nos vimos; no obstante, pusimos las mismas diligencias que en Buenos Aires, de valernos de lo que ya llevo dicho, que es la que todo lo puede; es cierto, señores, que yo he quedado tan admirado de ver que de los imposibles hemos sacado plata; luego yo digo bien que por amor de todos nosotros ha dado las providencias Su Divina Majestad, dándonos esfuerzo y salud y plata que gastar; así, pues, vuestras mercedes ríndanle mill gracias á Su Divina Majestad: cuando este pliego llegare á las manos de vuestras mercedes, pueden hacer lo que siempre acostumbran en el Cercado y en la iglesia de Nuestra Señora de Copacabana, disponiendo al Divinísimo patente con una misa cantada en hacimiento de gracias.

"El día Ig de Abril, en que celebra nuestra madre la Iglesia el patrocinio de nuestro padre y señor San Joseph, salimos del Río Janeiro para Lisboa, $y$ en el patrocinio de este gloriosísimo patriarca tuvimos feliz navegación, aunque muy dilatada, por haber sido de ciento y dos días, pues habiendo comenzado á navegar el día I9 de Abril, llegamos al puerto y corte de Lisboa el día 29 de Julio de 1650 . Aquí se renovaron nuestros sustos y cuidados, temiendo ser sentidos del embajador de España que asiste en dicha corte de Lisboa no nos hiciese algún desaire y nos viésemos en algún aprieto, como les había sucedido á otros españoles, por estar prohibido el tránsito por Lisboa. Mas Dios, Nuestro Señor, se dignó de librarnos de todo peligro y puéstonos en cobro nuestras personas, tratamos de pasar a Roma; más, descubrimos ser imposible de poder pasar. Lo primero, que el tránsito para Roma dista cuatrocientas leguas y hecho el cómputo de gastos que habíamos de tener hasta ponernos de vuelta á Madrid, no lo habíamos de hacer con dos mill pesos, porque unos padres que habían ido á Roma á negocios particulares nos aseguraron los gastos imponderables que habían tenido, y lo peor es que no consiguieron lo que pretendian. Con estas noticias tan manifiestas nos desanimamos, pesando las pocas fuerzas que teníamos, y en la mejor forma que pudimos, tomamos un consejo y nos valimos de un banquero, personaje tal y de créditos, y de mucha experiencia, por cuya mano remitimos el tanto para Su Santidad con un memorial ó petición en latín que hizo mi compañero el R.P. Cala, quien nos aseguró que vendría bien despachado el escrito, porque tenía buenos agentes en Roma, y para los costos y gastos le dimos cien pesos. Hechas estas diligencias nos pusimos en camino para la corte de Madrid el día 8 de Agosto, y el día 22 del mismo mes llegamos ả dicha villa de Madrid. 
"Habiendo llegado, procuramos con todo empeño el entregarle á Su Majestad, en mano propia, la exclamación que traíamos á favor de la Nación, y en cumplimiento de nuestro deseo, aquella misma noche pasamos al palacio, y nos aseguraron que era imposible de poder ver á $\mathrm{Su}$ Majestad sino tales y tales días, y esto pasando primero por el Consejo, que es lo que nosotros no queríamos. El día siguiente 23 nos salimos al campo donde iba Su Majestad á divertirse en la caza, y aunque nos habían ponderado mucho la dificultad que había en ver al Rey y poderle hablar, no obstante, á costa de riesgos y peligros, aún de la propia vida, le salimos al encuentro, metiéndonos por entre la chusma de soldados y le entregamos á Su Majestad (es de advertir que no paró la carroza de Su Majestad, sólo sacó la cabeza por dos veces) nuestro escripto dicho día 23. Y el día siguiente nos fuímos al palacio, y fue con tanta fortuna que encontramos con el señor Secretario de Cámara de Su Majestad, á quien preguntamos que si sabía algo del dicho escrito, á que nos respondió que Su Majestad le había leído y los señores ministros que le acompañaban y les habia causado gran novedad; y con el dicho señor secretario le remitimos á Su Majestad un papel escripto, dándonos a conocer, y luego Su Majestad le dijo que lo pusiese en forma de memorial con los otros papeles, y que todo junto lo entregase á los señores del Consejo de Indias, lo que ejecutó luego, sin dilación; esta y otra muchas veces nos vimos con el señor secretario. Luego pasamos al convento el día 24 y fuimos bien recibidos del Rmo. Padre Comisario de Indias fray Matías de Velasco, á quien mi compañero el R. P. fray Isidoro de Cala le notició el motivo de nuestra venida á España. Después de algunos días, por mandado del Rey, los señores consejeros hicieron llamar al dicho R.P. mi compañero para que declarase los agravios que hacían los españoles á los de nuestra Nación, la cual declaración hizo: por dos ocasiones: una con el señor Marqués de la Regalía, consejero de Indias, y la otra con el señor fiscal de dicho Consejo; en las cuales mi compañero alegó cuanto pudo á favor de nuestra Nación, expresando todos los agravios que padecíamos en ese reino del Perú, y juntamente por un escripto de su puño de cuatro fojas, de lo cual le vivo muy agradecido á dicho R.P. pues no siendo de nuestra Nación, quienes han discurrido que yo les engañaba, por cuyo motivo no han querido concurrir con dinero alguno para facilitar nuestra pretensión.

"También vivo muy quejoso de vuestras mercedes por no haber querido creer la palabra que les dí, de que en la primera ocasión que pudiese pasar á España lo había de ejecutar. Más, vuestras mercedes no lo creyeron 
y por eso no quisieron enviarme sus poderes, muy confiados en don Francisco Zeballos, mas Dios vuelve por mí, para que en nombre de todos los de la Nación pudiese seguir el pleito como se debe. Lo cierto es, señores míos, que si yo hubiera traído los poderes de vuestras mercedes, muchos pasos hubiera dado ya á favor de nuestra Nación; mas, lo que yo tengo visto es que vuestras mercedes saben remitir poderes parạ los extraños, que no procuran su bien y alivio sino la propria conveniencia y utilidad de ellos mismos; pero a mí, que me he puesto á tantos riesgos y peligros por el bien y libertad de la Nación, ni poderes ni carta alguna me han querido enviar.

"Luego que llegué á esta corte de Madrid ví un poder que remitió el Cabildo de esa ciudad de Lima el año pasado de 49, en los navíos que salieton del puerto del Callao, para don Juan Ladrón de Guevara y don Francisco Pérez Martín: jcuánto mejor hubiera sido que dicho poder hubiera sido para mí, y si no, para el padre misionero, mi compañero, que se ha expuesto á padecer todos los riesgos y peligros que le pudieran sobrevenir, sólo por amor de mí y de vuestras mercedes! Nada de esto saben apreciar, y solicitan á otros, que sólo pretenden dineros para tener qué comer: ¡así se les luce á vuestras mercedes el fiarse de los extraños! Pregunto yo: ¿qué es lo que han hecho los apoderados desde el año 35 hasta el presente? Pues, ni un paso dan por el bien de la Nación; solamente procuran éstos ver si viene alguna libranza de dinero para tener qué gastar. Así lo ejecutó su apoderado de vuestras mercedes (como le consta al señor don Juan de Bustamante Carlos Inca) don Francisco Pérez Martín, quien habiendo recibido doscientos pesos de don Diego Chuquiguanca, cacique principal del pueblo de Azángaro, para una pretensión, lo que ejecutó con dichos doscientos pesos fue hacer vestidos para sí y su mujer y regalarse muy bien. Mas, hasta ahora están por dar el primer paso en dicha pretensión, y esto más ha de un año, y si le remitiesen más dinero, hará lo proprio; y lo mismo digo de todos los demás agentes, pues sólo están á la mira de tener qué comer á costa de los indianos, y desde aquí les escriben dándoles muchas esperanzas, mas, en Ia realidad, no ejecutan cosa alguna á nuestro favor.

"Mi deseo, señores míos, es servir á vuestras mercedes mientras Dios me diese vida, ya que el Señor me ha puesto en esta corte de Madrid, donde los puedo aliviar, como lo ejecutó don Vicente Morachimo, cuando estaba en esta corte; si vuestras mercedes gustan de que yo sea su apoderado y vea por su alivio y consuelo, remítanme sus poderes generales en papel sellado y autorizado de escribanos, con algún dinero señalado 
para mantenerme cada año, y verán entonces practicando el amor que tengo á nuestra nación, de otra manera me parece imposible que vuestras mercedes puedan tener consuelo alguno, porque los demás agentes, como llevo dicho, sólo miran su proprio interés y conveniencia, como no les duele, aunque vengan los escriptos brotando sangre, no hacen caso ni aprecio alguno, sino del dinero, que es su único empeño y cuidado. Abran, pues, vuestras mercedes los ojos y miren con reflexión lo que tanto les importa, pues aunque yo me prive de ver á mis parientes, me quedaré en esta corte de Madrid para correr con sus dependencias, porque vuestras mercedes logren de verse libres de la tiranía y esclavitud que padecen.

"También es preciso que vuestras mercedes remitan dinero para pagar la deuda que hemos contraído en nuestro viaje, pues, como todo se ha facilitado á fuerza de plata, han sido los gastos muy crecidos; hasta la hora presente estamos debiendo más de seicientos pesos, y el gasto va corriendo en nuestro preciso sustento, porque en esta corte todo cuesta el. dinero y al indiano le llevan mas, porque discurren que todos vienen cargados de doblones. Si vuestras mercedes no nos ayudan en esta deuda que hemos contraído, no tenemos á quien ocurrir, ni hay quien se duela de nosotros; $y$ pues por amor de vuestras mercedes y de toda la Nación, nos vemos debiendo, suplicamos, por amor de Dios, que nos auxilien y socorran.

"El fundamento que yo ture para los gastos que se han hecho, es porque vuestras mercedes no dijesen de mí que, por no tener ánimo ni crédito, había dejado perder una ocasión tan buena; por eso y por haber nacido con obligaciones, y otras que ya diré, me ha hecho emprender empresa tan grande y empeñádome, en la esperanza de que vuestras mercedes me desempeñarán, como lo acostumbran vuestras mercedes cuando quieren volver por su punto y honra, como lo tengo yo visto que lo hicieron, empeñándose en las plausibles fiestas de la coronación de nuestro rey y señor Don Fernando el Sexto, que Dios guarde.

"También hemos movido á los agentes de vuestras mercedes don Juan Ladrón de Guevara y á don Francisco Pérez Martín, á fuerza de dinero que pedimos prestado, á que presentasen al Rey, nuestro señor, un memorial (con advertencia que no quisieron moverse los dichos agentes sin primero percibir la plata, lo que ejecutamos, dándole al uno is pesos y al otro 7 pesos y 4 reales de por acá), suplicando se dignase Su Majestad de dar una real cédula en que concediese franca licencia para que cualquiera indio noble pueda pasar á España á negocios y dependencias y con su caudal libre; dicho memorial está ya presentado al Consejo, aun- 
que todavía no lo han proveído; el dicho memorial lo hizo don Juan de Bustamante Carlos Inca, sin necesitar de abogado, y eso á instancias mías, pero de buena voluntad. Así me ha dicho que, como no sea dar plata, ni dado ni suplido, no puede, pero por su pluma y sus pasos lo hará con alma y vida. Un tanto de el dicho memorial tiene remitido mi compañero al R.P. fray Antonio Garro, por manos de don Manuel de Mansilla, que va de alcalde de corte á esa ciudad de Lima. Y, en fin, mucho hubiera yo hecho por vuestras mercedes si hubiera traído sus poderes; mas, como tengo las manos atadas, nada puedo ejecutar, por lo cual vuelvo á decir que en la primera ocasión que se of reciere me remitan sus poderes, del modo que llevo dicho, para que yo pueda presentarme con ellos y proseguir con lo que ya está empezado y trabajar nuevamente.

"También les participo á vuestras mercedes cómo el R.P. fray Francisco Venegas, uno de los custodios que fue á Roma al Capítulo General, quien como testigo de vista y también de esta corte, dirá lo que pasa en ella, á quien le he suplicado les desengañe á vuestras mercédes de fiarse de los extraños sus negocios. Así va el dicho R.P. bien informado de lo más mínimo de lo que pasa por acá.

"También he recogido muchos papeles de mucha importancia que estaban detenidos para presentárselos á Su Majestad en siendo tiempo, desde el año 35 y de 47 , tocantes al cacique Chuquiguanca, hijo del difunto don Joseph, y otros de otros caciques y otros de esa ciudad, como también un memorial adjunto con una carta de ese Cabildo, y otro memorial del P. Felipe de Mantilla, jesuíta, su fecha en Lima y Septiembre 27 de 1737 . Y el dicho padre es cura del Cercado, y dicho memorial es á nuestro favor y defensa de ese pueblo del Cercado.

"Mis señores: las primeras cartas que yo les he escrito á vuestras mercedes fue con mucha precisión, porque dentro de 24 horas se cerraban los cajones que iban para esa ciudad, por cuyo motivo no me quedó el borrador para poderme guiar para las duplicaciones, y así no me acuerdo de lo que puse de más o de menos, y también fue menos escrito que en éste, y así me he alargado por lo que pudiese suceder; no sea cosa que por pensar que es la duplicación lo dejen de leer.

"Señores: se me hace fuerza el volver al principio de mi narración, y así vuestras mercedes pongan atención á mi relación, para que si alguno estuviese de mala inteligencia, vengan en pleno conocimiento de mi proceder.

"Señores: para dar cumplimiento de lo que yo les ofrecí de ser su mensajero ó embajador, en nombre de toda la nación, dí principio de mi 
viaje desde esa ciudad sólo con 8 pesos, y ésos prestados, los cuales se los remití desde el camino (no como lo que han dicho que con más de 600 pesos había salido de esa ciudad) con la esperanza de que los caciques, y en particular los parientes del Cuzco, me habían de facilitar con plata; mas no sucedió así (eso es fiarse de hombres y más de parientes); finalmente, proseguí mi viaje, comunicando á unos, persuadiendo á otros, y por último llegué á la ciridad del Cuzco, en donde me entendí en comunicar y consultar sobre la materia, y alli sucedieron cosas particulares, que por no alargarme omito; entre todo esto, nunca desistí de mi determinación, siempre constante y animoso. ¿Quién puede hacer esto sino Dios? que por las cosas que me han acaecido lo he experimentado; por lo tanto, voy á manifestarles á vuestras mercedes. Pues viéndome sin esperanzas de socorro, ni de Lima ni de otras partes, determiné consultar con los mayores hombres de celo y de virtud, para que, según lo que saliese de la consulta, determinar de mi viaje; mas, salió al contrario de lo que yo esperaba, de grandes más dificultades, y la mayor era el que no había plata ni hombres que tal emprendiesen una empresa tan ardua; pero que por lo que mira de los escritos, importaba mucho el que Su Majestad lo supiese y Su Santidad también, para remediar tanta calamidad; y dijeron más los consultores, encareciendo grandemente que, si ellos fuesen indios habian de saltar por sobre tejados, que aunque supieran venir nadando sobre las aguas y comiendo yerbas, habían de venir á dar á saber á Su Majestad de lo que padecían, pero que los indios no lo harían, así por no haber hombres entre ellos y, sobre todo, que eran tímidos, y otras infinitas cosas dijeron, apocándonos. Habiendo, pues, entendido de la consulta lo referido, hice propósito de emprender mi viaje, y juntamente procuré disimular y hacer deshechas, y para divertirlos más, condescendí á hacer viaje á las montañas de Quillabamba, y cumplidos los tres meses volví á la ciudad del Cuzco. Mi compañero era uno de los que se halló en la consulta, á quien yo le persuadí á que mirase por nosotros y que se dignase de acompañarme, á que condescendió el dicho mi compañero, y cuando yo volví ya tenía las providencias para el viaje. Aséguroles ; vuestras mercedes, con la verdad que siempre ha profesado decir, así digo para aquí y para ante Dios, que con sólo 6 pesos que dió un cacique depuesto, llamado don Andrés Navarro, dimos principio á nuestro viaje en 25 de Septiembre de 49. Parece cosa incréible el cómo nos bandeamos en tan dilatado camino, como son 800 leguas hasta Buenos Aires, desde donde empezamos á buscar plata prestada pata no desistir de la empresa. La plata que hemos gastado hasta el presente pasan de 
dos mill pesos. Corrimos por la costa porque no nos prendieran en el camino, y cuando llegamos á Buenos Aires ya teníamos cartas requisitorias de mi Comisario General; en fin, por sobre todos saltamos; por esto dije que estuvimos escondidos tres meses.

"Señores, á mí me parece ser importante el que don Antonio Chaiguaca se pase á esta corte para ahorrar de abogados; vuestras mercedes procurarán animar á este dicho don Antonio, y en tanto que vea letra de vuestras mercedes, Dios, Nuestro Señor, guarde la vida de vuestras mercedes muchos y muy felices años en su amor.-Madrid y Noviembre I4 de 1750.-M. ilustre Cabildo, B.L.M. de vuestras mercedes, su más afecto pariente y seguro servidor.--La misma nada,--Hermano Calixto de San Joseph Tupac Inca". - (Con su rúbrica).

Págs. 544-545-546-547-548-549-550.

\section{ANEJO No 5}

"Digno es participar á vuestras mercedes de que nuestro pariente el dicho señor don Antonio (sic) de Bustamante Carlos Inga, es todo nuestro favorecedor, se da tanto amor y desinterés en las ocasiones que se han ofrecido, y nos debemos honrarnos de tener aquí una persona tan real. zada, como descendiente del gran Guayna Capac, pues así lo ostenta su persona, con el porte con que se mantiene en el empleo de gentil-hombre de boca de Su Majestad, empleo de mucha distinción en esta corte, estimado de Su Real Majestad y grandes de España por su sangre real y modales, con respectosas acciones, que hace revivir las atenciones que se deben á la majestad de la real sangre de estos monarcas, que fueron estos Incas emperadores, y así digo á vuestras mercedes es honra real, y también se mantiene con mucha decencia de criados, casa y con coche; y no me detengo más, sino guarde Dios.

"Vuestras mercedes no estrañen el que yo repita dos veces una misma cosa: el motivo es que las consultas se hicieron por tres y cuatro veces; una en San Borja con los P. P. de la Compañía, otra con los caciques, y de temor no quisieron dar sus firmas, porque dijeron que los escribanos lo habían de descubrir á los españoles. Otras dos en San Francisco, las que tengo dichas. 


\section{ANEJO N? 6}

"El Rey.-Por cuanto fray Calixto de San Joseph Inca, religioso lego de el Orden de San Francisco, me ha representado que habiendo venido á estos reinos de los de el Perú, su patria, con el encargo de poner en mis reales manos una Representación de aquellos indios, y ejecutádolo así en Agosto de mil setecientos y cincuenta, pasó después á solicitar el hábito de dicha Orden Seráfica, y habiéndolo conseguido en el año próximo pasado de mil setecientos cincuenta y dos y hecho su profesión, considerando sus prelados que mediante estar instruído en los distintos idiomas de aquellos países, podrá hacer algún fruto en ellos en servicio de Dios y mío, le han dado patente para que se restituya allá al colegio de misiones de Urubamba para entender en lo que se le encargue tocante á este sagrado ministerio, suplicándome que en esta atención y en la de que, sin em. bargo de haber sido recibido de mi benignamente y dignándome de dar orden para que se le costee su viaje de mi Real Erario, se teme que por haber venido sin las precisas licencias de mi Virrey, se le puede ocasionar, á su vuelta, alguna vejación, sea servido de expedir de mi real cédula auxiliadora, no sólo para que ni por éste ni otro algún ministro mío se le moleste por la razón dicha, sino para que, así ellos como los muy reverendos arzobispos, reverendos obispos y demás jueces eclesiásticos le dejen pasar libremente á su destino, y den en la parte que á cada uno toca el favor y auxilio que necesitare. $Y$ visto en mi Consejo de las Indias, he venido en condescender á esta instancia.

"Por tanto, mando á el expresado mi Virrey de el Perú, Audiencia de aquel reino y demás ministros enunciados, y ruego y encargo á el muy reverendo Arzobispo de Lima y á los reverendos obispos y demás prelados y jueces eclesiásticos de aquellos dominios, guarden, cumplan y ejecuten y hagan guardar, cumplir y ejecutar, según y en la parte que á cada uno correspondiere, en todo y por todo, precisa y puntualmente, esta mi real deliberación, sin poner en su contenido la menor contradicción ni embarazo, con pretexto ni motivo alguno, que tal es mi voluntad.

"De Buen Retiro, á diez de Julio de mil setecientos y cincuenta y tres.-Yo EL REY.-(Hay una rúbrica).-Por mandato del Rey, nuestro señor-Don Joachin Joseph Vásquez y Morales".--(Con su rúbrica).

"(Hay tres rúbricas).-Para que á fray Calixto de S. Joseph, lego de el Orden de San Francisco, no se le moleste ni ponga embarazo en el destino que lleva de sus prelados, antes se le dé el ayuda y auxilio que necesitare".

Págs. 550-551. 


\section{ANEJO No 7}

"Excmo. señor.-En carta de 22 de Noviembre de 1757 me previene V. E., de orden de Su Majestad, que de acuerdo con los superiores de fray Calixto de San Joseph, religioso mestizo, lego de San Francisco, lo remita á eśos reinos en partida de registro, á fin de que se le tenga en ellos siguiendo su regla en algún convento austero y al mismo tiempo le sea castigo de las sugestiones que ha movido, y cumpliendo con ella han concurrido sus prelados y navega en el navío San Martín, que regresa por el Cabo de Hornos á Cádiz, previniendo lo conveniente al presidente de la Casa de Contratación de Indias.

"En este intermedio se ha mantenido recluso en el noviciado y después en la enfermería de este convento grande, con particular encargo á los inmediatos superiores de ambas laboriosas oficinas que velasen sobre su conducta y estuviesen á la mira si comunicaba por escrito ó por interposición de otras personas con sus paisanos indios y mestizos, que por la inconstancia natural de su genio y por lo que despierten comunicando con otros ladinos del país, se dejan llevar fácilmente de cualquier novedad y lisonjera esperanza que se les proponga, cuya enfermedad pide siempre el avisado estudio de prevenirla y cortarla, como parece se ha conseguido, y observado en este tiempo que ni había echado raíces ni tenido progreso la inquietud que amenazó; que es cuanto en este asumpto puedo expresar á V. E. para que lo pase á noticia del Rey.

"Dios guarde á V. E. muchos años. Lima y Enero 30 de 1759.-Exmo. Señor.-Besa la mano de V. E. su humilde servidor,-El Conde de Superunda.-(Con su rúbrica).-Exmo. Señor Bo. Fray don Julián de Arriaga".

"Ha sido de la aprobación del Rey lo que V. E. expresa en carta de treinta de Enero de este año, de haber hecho embarcar en el navío San Martín al religioso mestizo, lego de San Francisco, fray Calixto de San Joseph, en conformidad de lo que se previno á V. E. en 22 de Noviembre de 1757 , pues de esta suerte se evitará la comunicación perniciosa que ha mantenido con sus paisanos los indios, y que con promesas aéreas les exija lo que no es debido.

"Dios guarde, etc. Madrid, 20 de Diciembre de I759.--Señor Conde de Superunda.-Fecho por duplicado".

Págs. 55I-550. 


\section{ANEJO N9 8}

"Muy Ilustre Señor Presidente--Fr. Calixto de San Joseph, religioso de la Orden de N. Padre San Francisco, hijo de la santa Provincia de Valencia, puesto á la obediencia de V. S., con la sumisión debida, dice: que el año de 55 pasó á estos reinos de España de orden de Su Majestad y á costa de su Real Erario, para entender en las misiones que hacen de las provincias de los Charcas, y el año 56 llegué á la Ciudad de Lima, donde me presenté á $\mathrm{S}$. E. con mi real cédula y patentes de mis Generales; y al tiempo de mi partida para ir á mi colegio de Tarija, me reclusaron de orden de S. E. por una leve sospecha (dicen) que tenía correspondencia con el levantado del Cerro de la Sal; y habiendo corrido desde el dicho año hasta el presente recluso en la casa grande, salió de resulta, sin embargo no haberse hallado en mi mácula alguna, que por que conviene en servicio de ambas Majestades vaya á los reinos de España y en partida de registro, en el navío de San Martín; y habiéndolo ejecutado con pronta obediencia, por volver á dicha provincia, hemos tenido el infausto arribo, y con esta ocasión me han dejado preso en este presidio de Valparaíso, sin señalarme el diario. $Y$ esperanzado que de cuenta de Su Majestad se me suministrara, he estado comiendo sobre fianza hace ya un mes; por lo que á V. S. suplico rendidamente se sirva mandar se me socorra con dicho diario de cuenta de la real hacienda de esa capital, por los motivos que llevo expresados, lo que espero merecer de la benevolencia y cristiandad de V. S.-Fr. Calixto de San Joseph".

Reunido el Real Acuerdo para proveer esta solicitud, determinó en 30 de Julio de aquel año que de fondos de penas de cámara se contribuyese al reo con dos reales diarios.

Págs. 550-553.

\section{ANEJO N? 9}

"Por justas causas que tuvo S. M. (que Dios haya) se previno al Virrey del Perú remitiese en partida de registro á fray Calixto de San Joseph, indio de nación y profeso en el convento del Espíritu Santo de la ciudad de Valencia, á efecto de que se le pusiese en uno de los de Castilla donde siguiese su regla y vida religiosa, sin ocuparse en las juntas y congregaciones de indios que movía en Indias, y respecto de haber avisado al Consejo el comisario general de ella, fray Matías de Velasco, había lle- 
gado á Cádiz este religioso, en su consecuencia ha mandado Su Majestad se prevenga á $\mathrm{V}$. $R$. le incorpore en uno de los conventos de las provincias de España distante de puerto de mar, como que le prohibe Su Majestad volver á Indias, encargando muy particularmente á su prelado de velar su conducta: lo que de su real orden aviso á V. R. para que en esta inteligencia lo ejecute así y participe su cumplimiento.

"Dios guarde á V. R. muchos. Buen Retiro, 9 de Diciembre de 1760. -Para el Comisario Gencral de San Francisco.

Pág. 550.

\begin{abstract}
ANEJO No IO
"Excmo. Señor.-Muy señor mío: En cumplimiento de el orden de Su Majestad que me ha comunicado V. E. en su apreciable papel de 9 del que rige, he destinado á fray Calixto de San Joseph, indio de nación, al convento de Recollección de San Francisco del Monte de la Provincia Observante de Granada, que está en desierto en la Sierra Morena, abstraído del comercio de seculares y distante del mar, y dado las demás providencias que V. E. se servirá ver en los papeles que acompañan y despachado por el correo de hoy. Espero que éstas merezcan la aprobación de Su Majestad y respectivamente de V. E.

"A cuya mayor obediencia quedo y rogando á Dios que guarde á V. E. muchos años, como deseo. San Francisco de Madrid y Diciembre á I2 de I760.--Excmo. Señor.-Besa las manos de V. E., su más obligado servidor y capellán.-Fr. Antonio Durán de Molina.-Excmo. Señor Bail.? Fr. Don Julián de Arriaga. M. S. M.
\end{abstract}

